\title{
Prevention measures and socio-economic development result in a decrease in malaria in Hainan, China
}

\author{
Shan-Qing Wang ${ }^{*}$, Yu-Chun Li', Zhi-Ming Zhang², Guang-Ze Wang ${ }^{1}$, Xi-Min Hu', Whitney A Qualls ${ }^{3}$
} and Rui-De Xue 4 $^{*}$

\begin{abstract}
Background: Historically, the incidence of malaria in the Hainan Province, China has been high. However, since 2001 the malaria incidence in Hainan has decreased due to large-scale, public educational, promotional campaigns and the adoption of preventative measures against malaria following the fast growth of socio-economic development. The present study analysed the correlation between prevention measures and social economic development on the incidence of malaria in Hainan from 2001 to 2013.
\end{abstract}

Methods: The data of malaria preventative measures and socio-economic development were collected from various cities and counties in Hainan Province from 2001 to 2013 and analysed by the grey correlation analysis system.

Results: Seasonal preventive medication and local fiscal revenue increases are significantly related to the reduction of malaria incidence from 2001 to $2013\left(R_{1}=0.751677 ; R_{5}=0.764795\right)$.

Conclusion: Malaria prevention and control measures and local economic development in Hainan decreased malaria incidence from 2001 to 2013.

Keywords: Malaria, Integrated vector management, Malaria preventative medication, Grey correlation

\section{Background}

Hainan Island is located in the southern part of China, with northern latitude $18^{\circ} 10^{\prime} \sim 20^{\circ} 10^{\prime}$, and eastern longitude $108^{\circ} 37^{\prime} \sim 111^{\circ} 03^{\prime}$. It has a population of 8.54 million, among which $83 \%$ are Han nationality, where $17 \%$ are minority. Hainan Island covers an area of 34 thousand square kilometer. Mountains and hills covering $38.7 \%$ of the area, mainly located at south central Island, are the main terrain of Hainan Island. The Island has an average temperature of $23.4-26.5^{\circ} \mathrm{C}$, with annual precipitation of 1437.0 - $3022.7 \mathrm{~mm}$ and annual daylight duration of 1573.5 - 2443.4 hours. Weather and environment are suitable for breeding of the malarial vectors, like Anopheles dirus and Anopheles minimus.

\footnotetext{
*Correspondence: wangsqkevin@163.com; xueamcd@gmail.com

'Hainan Provincial Centre for Disease Control and Prevention, Haikou 570203, China

${ }^{4}$ Anastasia Mosquito Control District, St Augustine, FL, USA

Full list of author information is available at the end of the article
}

Malaria has been reduced dramatically in China as a result of unprecedented governmental and international organizational efforts. Thirty million malaria cases were reported in 1949 in the People's Republic of China, which has since been dramatically decreased to 1,314 cases in 2011 [1,2]. In addition, during the same time, the epidemiological counts were decreased proportionally from 1,829 to 353 [3]. Hainan Province, located in the south of China, was one of the most important endemic malaria areas, with a high transmission of Plasmodium falciparum and Plasmodium vivax. Hainan implemented unprecedented measures for controlling malaria, such as mass drug administration (MDA) [4], long-lasting insecticide-treated mosquito nets (LLINs) [5], artemisinin-based combination therapy (ACT) [6], radical treatment [7], indoor residual spraying (IRS) [8], and chemoprophylaxis [9]. These methods have proven effective for controlling and preventing malaria transmission and there is no local- acquired case of $P$. falciparum reported in Hainan since 2009 [3]. 
In China, comprehensive prevention measures, including controlling malaria vectors and treating patients, were strongly encouraged and applied in the field with successful progress [10]. However, it is unclear which of the comprehensive measures implemented for controlling malaria were more effective. Statistical models, such as a logistic relation model, a negative binomial model, and a join point regress model have been applied to analyse the relationship between the incidence of malaria and climate, control measures and economic factors [11-13]. Grey relational analysis (GRA), is a useful tool for the selection of optimized factors from multiple performance characteristics, and has been applied in the field of engineering [14,15]. GRA models are derived from the grey system theory and used as a method for analysing relationship between outcomes and factors. GRA has gradually been applied to clinical evaluation, socio-economic and natural factors on the influence of malaria epidemics and experimental studies [16,17].

In this paper, the GRA method was used to make a comprehensive evaluation of the relationship between the incidence of malaria, human interventions in relation to malaria prevention and prevention measures following socio-economic development in Hainan, China.

\section{Methods}

\section{Data resource and collection}

Data were compiled from reports by the Ministry of Health and Malarial Control and Research in Hainan Province (2000-2013) on malaria incidence, the administration of primaquine, preventative measures in endemic seasons, the size of residual spraying areas, and the number of LLINs distributed [18]; collected from the Hainan Yearbook [19] were: socio- economic development of Hainan Province's gross domestic product (GDP), GDP per capita of Hainan Province, the provincial agricultural population, the number of rural laborers, the local finance income, per capita net income of rural households, rural residents, and rural health care spending per capita housing area.

\section{Analysis method}

The grey correlation analysis software GM (grey system theory and application of the third edition) was used [20].

To facilitate the analysis, the mean dimensionless processing model was used to sequence the comparison between the different dimensions and orders of magnitude. The formula below was applied:

$$
\xi_{i}(k)=\frac{\min _{i}\left(\Delta_{i}(\min )\right)+0.5 \max _{i}\left(\Delta_{i}(\max )\right)}{\left|x_{0}(k)-x_{i}(k)\right|+0.5 \max _{i}\left(\Delta_{i}(\max )\right)}
$$

where $K$ is the correlation coefficient representing the moment curve and the relative difference between the reference curve. Among the curves, the coefficient of 0.5 is used to distinguish between 0 and 1 of the general selection [21].

GRA uses the incidence of a disease (1/10,000) for the associated factors (X0/Y0); X1 represents the number of preventive medicine strategies; $X 2$ represents preventive medication dose rate (\%); X3 represents the resting phase effect on a radical cure medication number; X4 represents the resting phase effect on a radical cure medicine suit ratio (\%); X5 represents the retention area (sq $\mathrm{m}$ ) of the insecticide spray path (IRS); X6 represents LLINs. The social development factors, in order: Y1 represents Hainan Province (100 million yuan); Y2 represents GDP per capita; Y3 represents the provincial agricultural population (10,000); Y4 represents rural laborers (10,000); Y5 represents the local fiscal revenue (10,000 yuan); Y6 represents the per capita net income of rural households; Y7 represents the rural residents' health care expenditure; and, Y8 represents the rural per capita housing area (sq m). Data from 20012013 were entered into a computer software operating system item by item and the indices of correlation between the correlation factors and associated factors were conducted.

\section{Results}

\section{Control measures and the incidence}

The result showed that the control measures used were significantly related to the malaria incidence in Hainan Province, China ( $\mathrm{r} 1=0.751677$, r $2=0.60305$, r3 $=0.628916, r 4=0.563998, r 5=0.615526, r 6=0.661795$ ) (Table 1). The comprehensive preventative measures are ranked according to the significant impacts on malaria incidence reduction: preventative medicine $(\mathrm{X} 1)$, radical medication (X3), LLINs (X6), IRS area (X5), prevention medicine dose rate $(X 2)$, and radical medicine suit ratio (X4) (Figure 1). During the ten-year period, a popular seasonal preventive medication provided to the people of Hainan had the most significant relationship with the reduction of malaria incidence.

\section{Socio-economic development and malaria incidence}

The results showed that socio-economic development in Hainan Province was significantly related to malaria incidence $(\mathrm{r} 1=0.676872, \mathrm{r} 2=0.666447, \mathrm{r} 3=0.64267$, $\mathrm{r} 4=0.598968, \mathrm{r} 5=0.764795, \mathrm{r} 6=0.645387, \mathrm{r} 7=0.586146$, r8 $=0.635062$ ) (Table 2).

Socio-economic development has associations with the reduction of malaria incidence: local fiscal revenue $(\mathrm{Y} 5)>$ Hainan Province revenue $(\mathrm{Y} 1)>$ GDP per capita $(Y 2)>$ per capita net income of rural households $(\mathrm{Y} 6)>$ rural per capita housing area $(\mathrm{Y} 8)>$ rural resident health care expenditure $(\mathrm{Y} 7)>$ provincial agricultural population (Y3) > rural laborers (Y4) (Figure 2). 
Table 1 The correlation analysis of malaria incidence, malaria prevention and control measures

\begin{tabular}{|c|c|c|c|c|c|c|c|}
\hline \multirow[t]{2}{*}{ Years } & \multirow{2}{*}{$\begin{array}{c}\text { Incidence } \\
(1 / 10,000)(X 0)\end{array}$} & \multicolumn{2}{|c|}{ Preventive medicine (PM) } & \multicolumn{2}{|c|}{ Radical treatment (RT) } & \multicolumn{2}{|c|}{ Insecticides ${ }^{\#}$} \\
\hline & & No. of PM (X1) & $\%$ of PM $(X 2)$ & No. of RT (X3) & \% of finish RT (X4) & Area of IRS $\left(\mathrm{m}^{2}\right)(\mathrm{X} 5)$ & No. of ITNs (X6) \\
\hline 2001 & 5.95 & 23,202 & 95.78 & 17,162 & 96.6 & 642,031 & 29,717 \\
\hline 2002 & 6.92 & 27,725 & 96.5 & 28,903 & 93.01 & 0 & 26,669 \\
\hline 2003 & 7.84 & 20,093 & 95.16 & 26,538 & 97.42 & 988,165 & 31,098 \\
\hline 2004 & 11.52 & 6,504 & 96.21 & 10,026 & 99.68 & 869,996 & 57,551 \\
\hline 2005 & 5.46 & 29,239 & 96.69 & 25,109 & 98.65 & 506,935 & 58,624 \\
\hline 2006 & 4.66 & 122,024 & 93.04 & 44,203 & 98.88 & $1,049,305$ & 55,188 \\
\hline 2007 & 4.09 & 28,646 & 91.3 & 30,263 & 99.05 & 248,425 & 177,742 \\
\hline 2008 & 2.21 & 30,818 & 94.16 & 55,091 & 98.79 & 1,257 & 162,064 \\
\hline 2009 & 0.79 & 35,811 & 96.2 & 57,048 & 98.74 & 282,908 & 158,541 \\
\hline 2010 & 0.09 & 12,850 & 94.15 & 17,571 & 97.89 & 470,701 & 138,548 \\
\hline 2011 & 0.01 & 7,726 & 98.91 & 4,791 & 97.58 & 262,295 & 71,941 \\
\hline 2012 & 0 & 415 & 96.26 & 1,143 & 93.16 & 730,452 & 47,356 \\
\hline 2013 & 0 & 1,132 & 99.76 & 22 & 100 & 117,954 & 19,083 \\
\hline \multicolumn{2}{|c|}{ Correlation coefficient } & 0.7917 & 0.5527 & 0.7000 & 0.5389 & 0.6032 & 0.6592 \\
\hline
\end{tabular}

${ }^{\# 2.5 \%}$ Cyhalothrin.

\section{Discussion}

In 2010, the Chinese government decided to embark upon the national malaria elimination program (NMEP), with the goal of eliminating malaria by 2015 in the majority of China with the exception of the border region of Yunnan Province. In addition, the goal of elimination in the People's Republic of China was set for 2020. Furthermore, the Action Plan of China Malaria Elimination (2010-2020) (APCME) was issued by the Chinese government [10]. According to APCME standards, there were ten counties of high malaria incidence in Hainan Province.

The major factors used to reduce malaria incidence were the promotion and administration of preventative medicines, primarily primaquine, and the distribution of LLINs before the start of malaria transmission in endemic regions. The small correlation between the ratio of completed courses of radical medical treatment and the incidence of malaria in this study may suggest that it is also necessary to administer anti-malarial drugs. Recent progress in malaria control has renewed enthusiasm and interest in MDA as a potential strategy for elimination and eradication [22-24]. MDA has also been considered as a strategy to contain the recent emergence of artemisinin resistance in the Cambodia-Thai and ThaiMyanmar borders and Jiangsu Province [10,24,25].

The combination of anti-malarial drugs and LLINs have been followed by reports of a decline in transmission

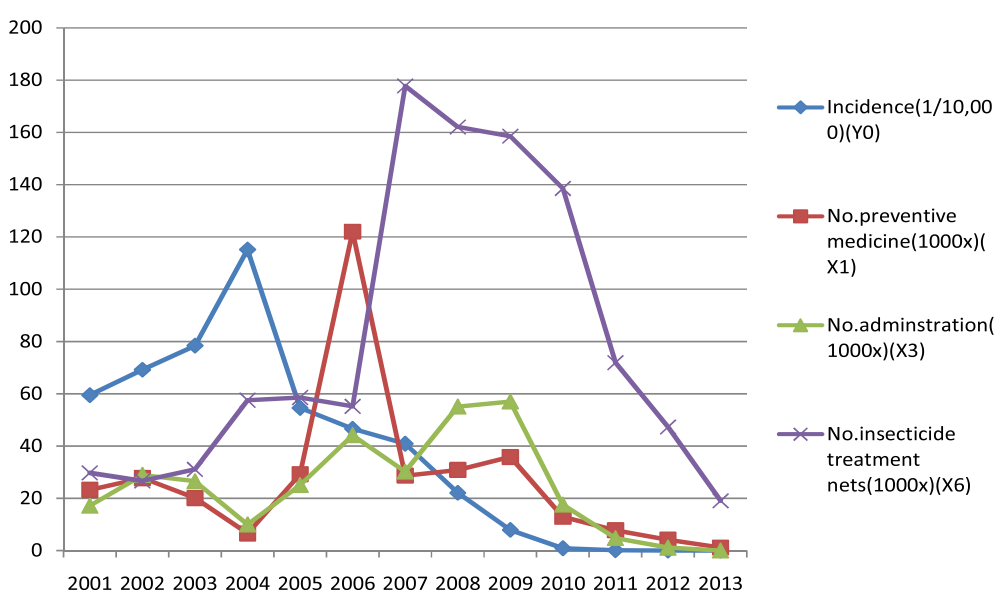

Figure 1 Relationship of malaria incidence and malaria prevention and control measures in Hainan Province, China from 2001 to 2013. 
Table 2 The correlation analysis of malaria incidence with socio-economic development in Hainan Province

\begin{tabular}{|c|c|c|c|c|c|c|c|c|c|}
\hline Years & (Y0) & (Y1) & $(\mathrm{Y} 2)$ & (Y3) & (Y4) & (Y5) & (Y6) & (Y7) & (Y8) \\
\hline 2001 & 5.95 & 579.17 & 7,315 & 567.19 & 229.53 & 495,924 & 2,285 & 39.1 & 19.61 \\
\hline 2002 & 6.92 & 642.73 & 8,041 & 570.43 & 233.53 & 518,324 & 2,423 & 62.23 & 19.16 \\
\hline 2003 & 7.84 & 713.96 & 8,849 & 574.9 & 240.27 & 615,971 & 2,588 & 96.05 & 19.51 \\
\hline 2004 & 11.52 & 819.66 & 10,067 & 501.15 & 250.04 & 692,965 & 2,818 & 86.57 & 19.92 \\
\hline 2005 & 5.46 & 918.75 & 11,165 & 505.3 & 256.01 & 848,930 & 3,004 & 93.00 & 21.82 \\
\hline 2006 & 4.66 & $1,065.67$ & 12,810 & 512.07 & 259.87 & $1,023,508$ & 3,256 & 110.92 & 22.05 \\
\hline 2007 & 4.09 & $1,254.17$ & 14,923 & 521.39 & 269.28 & $1,524,579$ & 3,791 & 95.55 & 22.64 \\
\hline 2008 & 2.21 & $1,503.06$ & 17,691 & 529.76 & 274.6 & $2,297,559$ & 4,390 & 123.82 & 22.84 \\
\hline 2009 & 0.79 & $1,654.21$ & 19,254 & 539.31 & 281.59 & $2,996,659$ & 4,744 & 129.26 & 24.00 \\
\hline 2010 & 0.09 & $2,064.5$ & 23,831 & 552.63 & 284.58 & $5,516,154$ & 5,275 & 138.35 & 24.74 \\
\hline 2011 & 0.01 & $2,515.29$ & 28,797 & 434.3 & 225.18 & $6,898,400$ & 6,446 & 175.52 & 25.35 \\
\hline 2012 & 0 & $2,855.26$ & 32,374 & 457.45 & 237.19 & $7,708,700$ & 7,408 & 201.72 & 26.12 \\
\hline 2013 & 0 & $3,146.46$ & 35,317 & 423.11 & 219.38 & $8,211,000$ & 8,343 & 227.18 & 26.59 \\
\hline Correlation coefficient & 0.6551 & 0.6479 & 0.5879 & 0.5490 & 0.7073 & 0.6420 & 0.6079 & 0.6405 & \\
\hline
\end{tabular}

Note: Y0-Incidence (1/10,000); Y1-GDP (100 million yuan); Y2- Real GDP per capita (yuan); Y3- Agricultural population (10,000); Y4- Rural workers (10,000); Y5- Local fiscal revenue (10,000 yuan); Y6- Per capita net income of rural households (yuan); Y7- Rural residents' healthcare expenditure (yuan); Y8- Rural per capita housing area (sq m).

of malaria in South Africa, Thailand, Rwanda, Ethiopia, and Zanzibar [26-29]. In China, deltamethrin-treated LLINs have reduced the density of indoor Anopheles minimus, a main vector in high malaria areas on Hainan Island, and reduced indoor mosquito-parasite transmission, but have not affected malaria transmission outdoors [30,31].

Pesticide residual spraying of an area was found to have little association with the decrease in the incidence of malaria. This relationship may be caused by the broad impact of preventative and curative measures and the lack of integrated vector management strategies available in Hainan [30]. In Kenya the effect of both IRS and Bacillus-based larvicides reduced malaria transmission and the number of clinical malaria cases in 2010 and 2011 [32]. The feasibility of IRS malaria control in Hainan Province needs to be studied further due to the influences of indoor and outdoor resting behaviors of the major vector mosquito, An. minimus.

Socio-economic development has a close relationship with people's physical health; it influences malaria incidence within the populations. According to the calculation, the results showed that the local fiscal revenue is significantly related to the malaria incidence, followed by

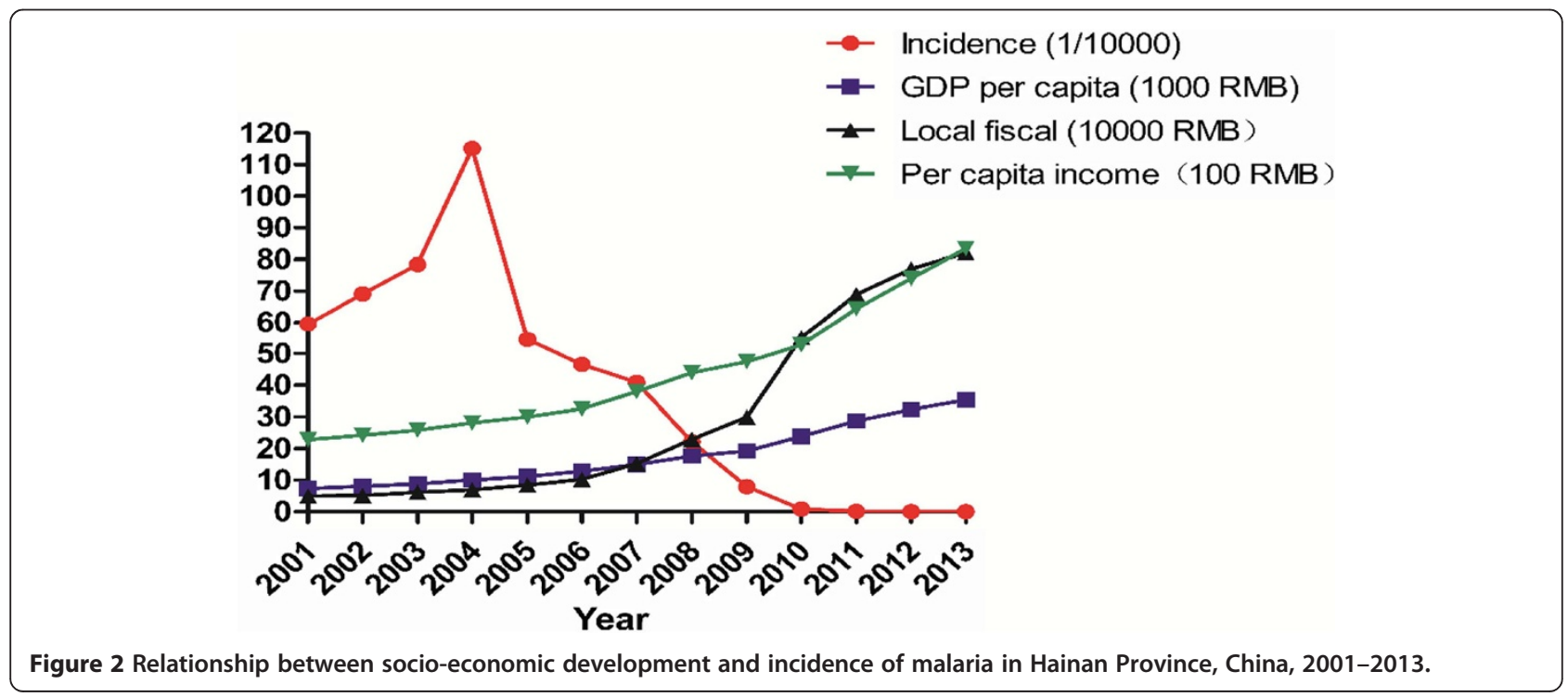


GDP in Hainan. Socio-economic development has increased local fiscal revenue and improved farmers' living conditions. This has directly reduced breeding sites for vector mosquitoes and drastically reduced the incidence of malaria. However, since there was little correlation between expenditure of rural residents and malaria incidence, this may indicate that farmers have not paid enough for medical care or healthcare expenses related to malaria treatment.

In addition to control and prevention measures, improving social and economic conditions, especially for ethnic minorities and in remote rural areas, is essential for malaria elimination in Hainan. The establishment of a network of medical treatment which provides a combination of malaria prevention and control along with basic public health services is necessary; promotion of health education and healthcare awareness are priorities for malaria control for minority groups in remote areas of Hainan Province, China [33,34].

\section{Conclusion}

The promotion of preventative measures through the administration of anti-malarial drugs, LLINs and radical treatment medication have benefited malaria control in Hainan Province, China. Socio-economic development, such as local and provincial economic growth and improved health conditions, have significantly reduced malaria incidence in Hainan Province, China from 2001 to 2013.

\section{Abbreviations}

ACT: Artemisinin-based combination therapy; GDP: Gross domestic product: GRA: Grey relational analysis; IRS: Indoor residual spraying; LLINS: Longlasting, insecticide-treated mosquito nets; MDA: Mass drug administration; NMEP: National malaria elimination program; APCME: Action plan of China malaria elimination.

\section{Competing interests}

The authors declare that they have no competing interests.

\section{Authors' contributions}

$S W, Y L, Z Z, G W$, and $X H$ were involved in the conceptualization, design, execution, and first draft of the manuscript. RDX and WAQ contributed to consulting, data analysis and interpretation of the results. All authors were involved in the preparation of the manuscripts. All authors read and approved the final manuscript

\section{Acknowledgements}

This study received financial support from the Hainan Provincial Scientific Research grant (Grant No 813251). Our thanks go to W D Gu, J M Scott, A Fulcher, and K Lizzi for reviewing/editing the manuscript.

\section{Author details}

'Hainan Provincial Centre for Disease Control and Prevention, Haikou 570203, China. ${ }^{2}$ Haikou Centre for Disease Control and Prevention, Haikou 571100, China. ${ }^{3}$ Department of Public Health Sciences, University of Miami Miller School of Medicine, Miami, FL, USA. ${ }^{4}$ Anastasia Mosquito Control District, St Augustine, FL, USA.

Received: 6 June 2014 Accepted: 28 August 2014

Published: 15 September 2014

\section{References}

1. Tang LH: [Achievements in the research on the prevention and treatment of malaria in China](in Chinese). Zhong Guo Ji Sheng Chong Xue Yu Ji Sheng Chong Bing Za Zhi 1999, 17:257-259.

2. Tang LH: [Malaria in China: from control to elimination] (in Chinese). Guo Ji Yi Xue Ji Sheng Chong Bing Za Zhi 2009, 36:8.

3. Yin JH, Yang MN, Zhou SS, Wang Y, Feng J, Xia ZG: Changing malaria transmission and implications in China towards national malaria elimination program between 2010 and 2012. PLoS One 2013, 8:e74228. doi:10.1371/journal.pone.0074228.

4. Hotez PJ: Mass drug administration and integrated control for the world's high prevalence neglected tropical diseases. Clin Pharmacol Ther 2009, 85:659-664.

5. Guillet P, Alnwick D, Cham MK, Neira M, Zaim M, Heymann D, Mukelabai K. Long-lasting treated mosquito nets: a breakthrough in malaria prevention. Bull World Health Organ 2001, 79:998.

6. Nosten F, White NJ: Artemisinin-based combination treatment of falciparum malaria. Am J Trop Med Hyg 2007, 77(Suppl 6):181-192.

7. Faucher JF, Bellanger AP, Chirouze C, Hustache-Mathieu L, Genton S, Hoen B: Primaquine for radical cure of Plasmodium vivax and Plasmodium ovale malaria: an observational survey (2008-2010). J Travel Med 2013, 20:134-136.

8. Pluess B, Tanser FC, Lengeler C, Sharp BL: Indoor residual spraying for preventing malaria. Cochrane Database Syst Rev 2010, (4). Art. No.: CD006657. doi:10.1002/14651858.CD006657.pub2.

9. Jeong S, Yang HW, Yoon YR: Evaluation of the efficacy of chloroquine chemoprophylaxis for vivax malaria among Republic of Korea Military Personnel. Parasitol Intern 2013, 62:494-496.

10. Ministry of Health of China: Action Plan of China Malaria Elimination. Beijing, China: Ministry of Health of China's Press; 2010-2020. in Chinese.

11. Zhang WY, Wang LP, Fang LQ, Ma JQ, Xu YF, Jiang JF, Hui FM, Wang JJ, Liang S, Yang H, Cao WC: Spatial analysis of malaria in Anhui province, China. Malar J 2008, 7:206.

12. Hsiang MS, Hwang J, Tao AR, Liu YB, Bennett A, Shanks GD, Cao J, Kachur SP, Feachem RGA, Gosling RD, Gao Q: Mass drug administration for the control and elimination of Plasmodium vivax malaria: an ecological study from Jiangsu province, China. Malar J 2013, 12:383.

13. Alexander N, Moyeed R, Stander J: Spatial modeling of individual-level parasite counts using the negative binomial distribution. Biostatistics 2000, 1:453-463.

14. Kuo YY, Yang TH, Huang GW: The use of grey relational analysis in solving multiple attribute decision-making problems. Comput Indust Eng 2008, 55:8055E.

15. Huang SJ, Chiu NH, Chen LW: Integration of the grey relational analysis with genetic algorithm for software effort estimation. Europ J Operat Res 2008, 188:898ERLI.

16. Luo FZ, Han YH, Li ST: [Large-scale complicated project strategic alliance partner selection-based on the combination of empowerment grey correlation evaluation](In Chinese). Technoeconom Manag Res 2013, 1:8-11.

17. Zhang $Z X, B i Y$ : [Primary analysis of relative degree of gray system on malaria incidence and antimalarial measures](In Chinese). J Pract Parasit Dis 1998, 6:116-117.

18. Wang SQ, Du JW, Hu XM: [Research On Malaria Prevention And Treatment In Hainan Province](In Chinese), Volume 6. 1st edition. : Hainan Publishing House; 2012:148-159. 180-205.

19. The people's Government of Hainan Province: [Hainan Yearbook (2001-2013). (In Chinese). Haikou, Hainan, China: Government of Hainan Province's Press;

20. Liu SF: [The Grey System Theory And Its Application. (In Chinese). Beijing: Science Press; 2011.

21. Liu XH: [The spectrum efficiency on immunity from the impact of Astragalus membranaceus study] (in Chinese). J Chin Herbal Med 2012, 35:1978-1981.

22. The malERA Consultative Group on Drug: A research agenda for malaria eradication: drugs. PLoS Med 2011, 8:e1000402.

23. Cotter C, Sturrock HJW, Hsiang MS, Liu J, Phillips AA, Hwang J, Smith-Gueye C, Fullman N, Gosling RD, Feachem RGA: The changing epidemiology of malaria elimination: new strategies for new challenges. Lancet 2013, 382:900-911.

24. Maude RJ, Socheat D, Nguon C, Saroth P, Dara P, Li GQ, Song JP, Yeung S, Donforp AM, Day NP, White NJ, White LJ: Optimizing strategies for Plasmodium falciparum malaria elimination in Cambodia: primaquine, 
mass drug administration and artemisinin resistance. PLoS One 2012, 7:e37166. doi:10.1371/journal.pone.0037166.

25. World Health Organization: Consideration of mass drug administration for the containment of artemisinin-resistant malaria in the Greater Mekong subregion, Report of a consensus meeting, 27-28 September 2010. Geneva, Switzerland: World Health Organization; 2011.

26. Barnes KI, Durrheim DN, Little F, Jackson A, Mehta U, Allen E, Dlamini SS, Tsoka J, Bredenkamp B, Mthembu DJ, White NJ, Sharp BL: Effect of artemether-lumefantrine policy and improved vector control on malaria burden in KwaZulu-Natal, South Africa. PLoS Med 2003, 2:e330. doi:10.1371/journal.pmed.0020330.

27. Nosten F, Van Vugt M, Price R, Luxemburger $C$, Thway KL, Brockman A, McGready R, ter Kuiye F, Looareesuwan S, White NJ: Effects of artesunatemefloquine combination on incidence of Plasmodium falciparum malaria and mefloquine resistance in western Thailand: a prospective study. Lancet 2000, 356:297-302.

28. Otten M, Aregawi M, Were W, Karema C, Medin A, Bekele W, Jima D, Gausi K, Komatsu R, Korenromp E, Lowbear D, Grabowsky M: Initial evidence of reduction of malaria cases and deaths in Rwanda and Ethiopia due to rapid scale-up of malaria prevention and treatment. Malar J 2009, 8:14.

29. Bhattarai A, Ali AS, Kachur SP, Martensson A, Abbas AK, Khatib R, Al-mafazy A, Ramsan M, Rotllant G, Gerstenmaier JF, Molteni F, Abdulla S, Montgomery SM, Kaneko A, Bjokman A: Impact of artemisinin-based combination therapy and insecticide-treated nets on malaria burden in Zanzibar. PLoS Med 2007, 4:e309. doi:10.1371/journal.pmed.0040309.

30. Zhang ZX: [The effect control of Anopheles minimus and Anopheles sinensis by deltamethrin treatment nets](In Chinese). Chin J Parasit Dis Control 1991, 4:257.

31. Wang WM: Jiangsu malaria prevention of grey relation analysis (In Chinese). J Practl Parasit Dis 1996, 4:107.

32. Zhou G, Afrane YA, Dixit A, Atieli HE, Lee MC, Wanjala CL, Beihe $L B$, Githeko AK, Yan G: Modest additive effects of integrated vector control measures on malaria prevalence and transmission in western Kenya. Malar J 2013, 12:256

33. Gu ZC, Deng D, Tang LH: [Grey correlation analysis on social factors and malaria endemic](In Chinese). Zhong Guo Ji Sheng Chong Xue Yu Ji Sheng Chong Bin Za Zhi 1993, 11:108-110

34. He CH, Hu XM, Wang GZ, Zhao W, Sun DW, Li YC, Chen CX, Du JW, Wang SQ: Eliminating Plasmodium falciparum in Hainan, China: a study on the use of behavioral change communication intervention to promote malaria prevention in mountain worker populations. Malar J 2014, 13:273.

doi:10.1186/1475-2875-13-362

Cite this article as: Wang et al:: Prevention measures and socioeconomic development result in a decrease in malaria in Hainan, China. Malaria Journal 2014 13:362.

\section{Submit your next manuscript to BioMed Central and take full advantage of:}

- Convenient online submission

- Thorough peer review

- No space constraints or color figure charges

- Immediate publication on acceptance

- Inclusion in PubMed, CAS, Scopus and Google Scholar

- Research which is freely available for redistribution 